\title{
Learning from peer feedback on student-generated multiple choice questions: Views of introductory physics students
}

\author{
Alison E. Kay, Judy Hardy, and Ross K. Galloway \\ School of Physics \& Astronomy, The University of Edinburgh, James Clerk Maxwell Building, \\ King's Buildings, Peter Guthrie Tait Road, Edinburgh EH9 3FD, United Kingdom
}

(Received 9 July 2017; published 6 April 2018)

\begin{abstract}
PeerWise is an online application where students are encouraged to generate a bank of multiple choice questions for their classmates to answer. After answering a question, students can provide feedback to the question author about the quality of the question and the question author can respond to this. Student use of, and attitudes to, this online community within PeerWise was investigated in two large first year undergraduate physics courses, across three academic years, to explore how students interact with the system and the extent to which they believe PeerWise to be useful to their learning. Most students recognized that there is value in engaging with PeerWise, and many students engaged deeply with the system, thinking critically about the quality of their submissions and reflecting on feedback provided to them. Students also valued the breadth of topics and level of difficulty offered by the questions, recognized the revision benefits afforded by the resource, and were often willing to contribute to the community by providing additional explanations and engaging in discussion.
\end{abstract}

DOI: 10.1103/PhysRevPhysEducRes.14.010119

\section{INTRODUCTION}

PeerWise $^{1}$ is an online application where students generate a bank of multiple choice questions for their classmates to answer. After answering the questions, students are encouraged to provide feedback to the question author about the quality of the question in the form of a numeric rating and/or as a free-response comment. PeerWise highlights the value of students' input "beyond reading... and listening" [1] and towards the creation of new resources to enhance the learning of both the individual student and the peer group as a whole [1-5]. By providing opportunities for students to make a tangible contribution, question generation activities give students ownership and control of their learning [4]. Students are also able to create materials emphasizing what they view as important and valuable, rather than simply responding to the priorities of teaching staff [6]. Giving students ownership is an important factor in developing independent thinkers and fosters deeper engagement with, and motivation for the learning process $[7,8]$.

The purpose of the present study is to explore student attitudes towards the PeerWise system to ascertain whether they believe that giving feedback on PeerWise can enhance

\footnotetext{
*alison.kay@ed-alumni.net

${ }^{1}$ https://peerwise.cs.auckland.ac.nz/.
}

Published by the American Physical Society under the terms of the Creative Commons Attribution 4.0 International license. Further distribution of this work must maintain attribution to the author(s) and the published article's title, journal citation, and DOI. their learning, how they decide what to write when providing feedback and how they use and benefit from the feedback they give to and receive from their peers through commenting. Asking students directly about their experiences affords the opportunity to investigate whether they are using the system in the manner originally intended by course staff, and if not, to explore the reasons why. It is also important to disentangle the degree to which students find benefit from the exercise and engage to maximize these benefits, in contrast to merely completing an assessment requirement. If students are not engaging with PeerWise in the manner intended, they may not be reaping maximum benefits from the system. Equally, if students find one particular activity too onerous, or prefer another aspect of the system, staff may be able to modify the assignment in order to maximize student engagement.

In using PeerWise, the roles of student and teacher are significantly blurred: not only do students generate a large question bank for the benefit of the entire cohort, they also engage in peer assessment and feedback. These aspects of the system enable PeerWise to be further categorized within the contributing student framework as being grounded in a "constructive evaluation" approach [9]. The functionality of PeerWise enables students to evaluate the quality of contributed questions, give and receive peer feedback and improve self-assessment skills. It offers students multiple opportunities to take ownership of their learning and actively engage with the assessment process, thus promoting deeper understanding of course materials and developing skills of self- and peer assessment, reflection, and self-regulation $[10,11]$ — key skills necessary to succeed in 
scientific endeavour, and indeed, more generally within the modern workplace [12].

This variety of tasks also has the potential to promote the development of both knowledge and understanding as well as the higher-order skills of problem solving and evaluation. Asking questions and providing explanations necessitates that students engage in "generative thinking" [13] - engaging with concepts and information beyond that which has already been made explicit in course materials - to synthesize information. In answering and commenting upon questions, students develop evaluative skills in relation to their own learning as well as to the subject area, and thus increase their metacognitive awareness.

In previously published work, the relationship between students' engagement with PeerWise and exam attainment across a number of physics, chemistry, and biology courses has been investigated using quantitative methods [14,15]. This showed that engaging with PeerWise through writing, answering, and commenting on questions is generally positively associated with end of course exam performance, even when controlling for a student's level of ability. However, quite a substantial variation in the level of PeerWise activity has been reported, both within and between courses [16]. Although most students write the minimum number of questions, a small number of students may contribute three or four times the minimum requirement. Conversely, most students answer and comment on far more questions than is required of them.

\section{BACKGROUND}

Providing feedback by commenting on student questions encourages reviewers to engage critically with the subject matter to identify problem areas and to provide advice or guidance as to possible solutions and improvements that could be made [17]. It is well established that teaching or explaining a concept to others is an effective method of determining whether a concept is truly understood [8]. When students need to go beyond their immediate initial understanding in order to critically engage with another student's work and provide explanations and justifications for their critique, they may have to extend their knowledge to be able to articulate their point of view [18], and to resolve conflicts between their originally held knowledge framework and the new information to be assimilated into it [18].

After having given feedback, students may be encouraged to reflect on and improve their own performance in light of their exposure to the standards set by their peers, and perhaps having developed a deeper understanding and internalization of assessment criteria [19-22]. Given the variety of ways feedback may be delivered and the myriad reasons for its implementation, it is perhaps not surprising that there is a huge body of research investigating student attitudes towards giving and receiving peer feedback and the characteristics of effective feedback and evaluation [23]. That said, there is a relatively limited amount of published work which aims to quantify how engaging with peer feedback impacts upon academic performance [21]. In a review of peer assessment literature, out of 26 studies cited, 15 focused on student attitudes while only 5 on domain specific skills [23].

\section{A. Student views on feedback}

A common theme of dissatisfaction amongst students, as highlighted in student satisfaction surveys, is the quantity and quality of feedback given to them throughout their studies. In the 2015 National Student Survey (a UK-wide survey of final year undergraduate students) [24], only $60 \%$ of Scottish full-time students definitely or mostly agreed that feedback was received promptly, $64 \%$ that comments were detailed, and $62 \%$ that feedback helped with clarification of things that were not understood. This is in comparison to views expressed on other issues such as the quality of teaching, the level of academic support or resource and IT provision, where between $80 \%$ and $90 \%$ of students responded favorably [24]. Students often feel that they do not understand feedback that has been given-it may be couched in academic jargon, or it may simply be illegible [25]. Feedback may also be given to students too late for it to make a difference to their learning in a particular course-a side effect of increasing modularization in education, where content is compartmentalized [26]. As a result, academic staff report that students do not even collect feedback that has been provided [27]. This leads to a failure by students to apply feedback from one particular course to a different academic context - they often do not recognize how to transfer advice from one subject area to the next [27].

Despite the desire for more feedback, students often do not respond to peer feedback in the same way as they do to instructor provided feedback [28]. Most students do however recognize the benefits of receiving potentially a larger quantity of feedback from multiple peers than perhaps may be given by teaching staff [29-31]. If students believe peer feedback to be helpful then they will be more likely to act upon it, despite it not originating from a teacher [30]. Students may, however, lack confidence in the quality of the feedback given to them by fellow students [10], as well as in their own ability to provide feedback-feeling that they are not experts and that it is the tutor's role to critique their peers $[29,32]$.

It could be argued that students need scaffolding and guidance when engaging in feedback tasks to ensure they feel confident in providing reviews. In a study evaluating a feedback activity where guidance had been provided, students reported a positive experience of peer review and that they had learned from the process and made changes to their own work in light of it. Students also stated they had learned to think more critically and view their own work from the point of view of the assessor and that actively giving feedback helped them develop skills of self-regulation and reflection more than just passively receiving it. [31]. 
In another study, student peers and expert academics reviewed undergraduate students' draft submissions in a research methods course [30]. There was no difference in the perceived helpfulness of feedback from peer and expert reviewers; however, undergraduates gave far less "directive" feedback than experts, instead highlighting where changes should be made, without suggesting a specific improvement. This is perhaps unsurprising, given the higher level of knowledge and experience needed to identify and specify how something could be improved $[17,21]$. Nevertheless, it is consistent with the fact that students find giving feedback a challenging task and are sometimes skeptical about the validity of peer feedback [30]. As with all learning activities, if students understand that giving feedback is a valuable and important task in itself, and that any useful feedback obtained is a bonus [33], they might be more willing to engage critically and develop more confidence in assessing their peers' work.

There is a large body of literature examining good practice in giving effective feedback and how to encourage students to make use of the feedback they receive [34-36]. In-depth discussion of this is beyond the scope of the current work; however, it would seem that an online mechanism such as PeerWise, where peers could provide immediate feedback, might enable a larger volume of feedback to be generated. Moreover, students would gain the benefit of engaging with the viewpoints of a wider range of people than just their tutor or one or two peer assessors, thus creating opportunities for richer discussions [37].

\section{B. Is it better to give or to receive?}

The provision of feedback plays a key role in the learning process for both the assessor and the assessed, as the focus is on developing shared meanings and negotiating shared understandings through student interactions. Feedback may encourage students to consider different perspectives, aiding their arrival at a solution to a problem or, more generally, their understanding. Students may even inspire each other, co-constructing knowledge and understanding [38] and paying attention to the quality of their own and their peers' work. This promotes a greater sense of accountability and responsibility towards not just their own learning, but also that of their peers [28].

By giving students responsibility for sourcing their own feedback and critiquing the work of others-and by extension their own progress, through a similar evaluation of their own work - they are able to maintain their ability to learn effectively beyond the university environment [39]. Learning environments need to offer students opportunities to actively seek feedback in a safe manner, with views shared both between students and between students and staff in a formative, nonthreatening, low-stakes manner [39].

As with all learning activities, regardless of the structure of peer assessment tasks, the environment in which they are carried out, or whether they are summative or formative in nature, students should understand the relevance and importance of the exercise. Feedback and assessment tasks should not be considered simply a hoop to jump through, or a tick-box exercise to be completed, otherwise students will quickly lose motivation and will engage in a surface learning approach to get the task over and done with as quickly as possible [40]. By failing to recognize the potential opportunities for enhancing their understanding, students will not gain as much benefit from the exercise as they should-further perpetuating their belief that peer assessment is not a worthwhile task, and perhaps more concerning, missing out on opportunities to develop their skills of self-regulation [41].

\section{Giving feedback}

Engaging with questions for the purposes of providing feedback in the form of a rating, a comment, or to ascertain the cognitive level of the question, is a cognitively demanding task. It forces students to think critically about the question and further develop their evaluation skills $[8,11,42]$. Most of the studies that look at the benefit of reviewing to the reviewers examine how reviewing can improve writing skills $[17,30,43]$ — reviewers are engaging in critical evaluation of and providing justifications for their conclusions [21].

When comparing assessments written by students who had either reviewed, read, or not engaged with their peers' papers, Cho and McArthur [43] found that those who participated in reviewing wrote the highest quality papers themselves. The active nature of evaluating and responding to the texts gave a benefit that reading alone did not. It was necessary to engage with the texts at a deeper level in order to provide an effective critique. This in turn led to an improved understanding of how to develop their work.

In an analysis of peer reviews of physics laboratory reports, Cho and Cho [21] found that students of all abilities could identify strengths in reports, but high ability students could identify more weaknesses. In other words, the higher the reviewer's writing skill, the more weaknesses which could be identified. In a similar study, Li, Liu, and Steckelberg [22] found a positive relationship between the quality of feedback students provided to their peers on a first draft of a project report and the quality of their own drafts. Moreover, the higher the quality of feedback provided by the reviewer, the better the reviewer's subsequent performance on their own project.

These findings also highlight a confidence issuestudents with a high level of confidence in their own ability might feel more able to critique the work of another student than a student who has little faith in their own ability. Students' lack of confidence is often cited as a barrier to engaging with peer assessment tasks. Students can be uncomfortable with others critiquing their work and they in turn are uncomfortable in assessing their peers [10]. This is not surprising - peer assessment is a difficult task 
and students lack experience in critiquing others' work and have little or no experience of marking or applying standards - tasks that carry a significant responsibility [44].

However, identifying problems in their peers' work may enable students to more readily identify (and address) problems in their own work, and provide them with a better idea of how their own work will be interpreted [31]. Exposure to all standards of work also helps students to assess the quality of their own performance more effectively [45].

\section{Receiving feedback}

Although studies by Cho and Cho and Li et al. [21,22] demonstrated a positive relationship between giving comments and performance, both studies also revealed that receiving comments was not so beneficial-that the only type of received comment to have any effect was "strength comments" (such as praise) on surface features of their writing. This, however, had a negative effect on the quality of the revised draft, possibly because the students had become complacent [21].

This seems somewhat counterintuitive. It would be reasonable to assume that receiving quality feedback would increase the quality of subsequent work. However, it is possible that students may perform well regardless of the quality of feedback received. Li et al. [22] showed that there was a significant positive relationship between the quality of final project reports and a student's ability to judge the quality of feedback received on earlier drafts (after controlling for the quality of the student's initial project draft and the quality of peer review they provided for others). Incorporating more good comments and fewer misleading comments is associated with greater improvement in project marks [28].

One implication for PeerWise is that, given the abundance of comments submitted and the inevitable variability in quality, students need to be able to distinguish between comments that will enhance their future performance and those that provide unhelpful or misleading information. Of course, acting upon and actively engaging with feedback is essential if performance is to be improved. Students need to be encouraged to actually use feedback-to close the feedback loop [46].

However, other studies have shown that receiving positive, reinforcing feedback is associated with increased performance $[20,47]$. While this appears to be in conflict with the studies discussed above [21], there are a number of possible reasons for this. Praise may increase intrinsic motivation and feelings of self-efficacy, which in turn encourages engagement with tasks, thus enhancing performance. Receiving praise along with cognitive feedback may also encourage students to approach the feedback positively, thus increasing the likelihood of acting upon recommendations [20].

In a study examining how different types of peer feedback affected undergraduate writing performance, Nelson and Schunn [17] focused on two "mediating factors": the cognitive factor of understanding the feedback and the affective factor of agreeing with it. If a student understood the feedback provided they were more likely to implement feedback. Similarly, it has been demonstrated that weaker students benefitted from receiving feedback if these comments were justified and explained to them-regardless of the actual quality of the feedback [48].

Justifications and extended explanations may enable students to understand where the problems lie, as otherwise they might lack the awareness required to identify problems in their own work. Being aware of the justifications for giving the feedback perhaps enables students to more readily decide whether the feedback is of good quality, with the potential to enhance their work, or whether it is of poorer quality, and therefore should be disregarded. Weaker students, or those lacking in confidence, may also be more influenced by any feedback, regardless of its quality. These students would therefore be more likely to implement poor quality feedback without evaluating it. That said, receiving justifications for feedback comments might not only benefit weaker students. Perhaps not surprisingly, one study found that $75 \%$ of students wanted comments that not only corrected mistakes and indicated areas of improvement, but which also explained why their answers were wrongto enable them to develop their skills and understanding [49].

Regardless of the format, quantity or quality of the feedback given, in order for any feedback to be effective, it must be acted upon rather than just left as "dangling data" [50], which is ineffectual at bridging the gap between the actual and desired levels of performance.

\section{FEEDBACK ON PEERWISE}

The nature of PeerWise means that students need to invest in the system in order for it to be effective. Questions must be submitted by students for other students to answer and students must provide feedback in order to instigate discussion and share knowledge. Without buy-in from students, maximum benefits will not be recouped-a failure to construct questions will mean a limited bank of questions for practice and discussion. If students do not discuss the questions and give feedback to the question author and to previous commenters, such feedback opportunities are passed up.

Few studies have investigated students' attitudes towards PeerWise. Of these, students were found to be largely positive about the system and felt that it benefitted their learning - increasing their depth of knowledge and understanding and forcing them to engage with course materials [51-53]. Students were also generally positive about the value of creating a large PeerWise question bank where they can test their knowledge and revise for exams [54,55].

Frequent concerns raised by students in previous PeerWise studies regard question quality, and lack of confidence that their peer group would self-correct any errors [54,56-58]. Students have also reported concern 
about poor quality feedback provided by their peers in PeerWise [55]. It is possible that these concerns will vary between courses - students in their first years may not have had much exposure to peer assessment techniques and so might be apprehensive; some institutions and certain types of courses incorporate peer assessment more frequently than others, so the peer assessment element may be familiar territory for some students, while being unknown and daunting for others. In one study of PeerWise use, $41 \%$ of second year veterinary medicine students agreed with the statement "Did it matter to you that not all the questions were reviewed by academic staff?", while only $17 \%$ of third year students agreed with the same statement [54] - perhaps demonstrating that with a little more experience, students become better able to handle the uncertainties of peer assessment and feedback, and appreciate the benefit that engaging with such activities can have.

As outlined in the preceding sections, the learning benefits of receiving feedback are limited by the extent to which students incorporate the feedback into their future performance. There is, however, a lack of research examining the extent to which students actively engage with peer feedback and how beneficial they find this aspect of the system. It is the aim of this paper to provide some insight to address this gap.

\section{METHODS}

PeerWise was used in two first-year undergraduate physics courses (Physics 1A and Physics 1B), across three academic years, at a research-intensive Scottish university. Instructors were motivated to use PeerWise by a desire to promote deeper engagement with course materials and the development of higher-order skills. PeerWise was incorporated as part of wider curriculum changes to promote active learning, for example, through the adoption of electronic voting, Peer Instruction episodes, and the flipped classroom approach.

\section{A. Physics 1A}

Physics 1A is a Scottish first year, first semester introductory physics course focusing on Newtonian mechanics. Scottish students comprise about half of the cohort. Although all students should have performed well in physics at the school level, there is a wide range of physics (and mathematical) backgrounds. Students having undertaken A-level or Advanced Higher school qualifications are all likely to have already encountered many of the concepts in Physics 1A in their previous studies; however, there are differences in the content of the syllabi between the different school qualifications. Students from Scottish schools may enter with only Higher Level physics - a lower level qualification, with less overlap in the material covered. There are also a number of students who have been educated outside the UK, which further increases the diversity in entry levels of physics knowledge and understanding. A key aspect of the course is, therefore, to ensure all students attain the same level of knowledge and
TABLE I. Physics 1A student demographics.

\begin{tabular}{cccccc}
\hline \hline & $n$ class list & $n$ male & $n$ female & $n$ major & $n$ nonmajor \\
\hline $2011-12$ & 207 & 151 & 56 & 77 & 130 \\
$2012-13$ & 287 & 233 & 54 & 101 & 186 \\
$2013-14$ & 248 & 182 & 66 & 114 & 134 \\
\hline \hline
\end{tabular}

understanding to prepare them for their future studies, regardless of their level of preparedness on entry.

Students attend whole class lectures (incorporating Peer Instruction episodes) and weekly interactive workshops. Workshops are led by a member of the academic staff, supported by postgraduate teaching assistants, and focus on problem solving in a small-group environment. The end of course exam follows an open book format and includes short and long answer questions. There is no multiple choice component in the exam.

As shown in Table I, there are significant variations across the years in terms of number of students and the balance between majors and nonmajors. Perhaps most striking is the disparity between the numbers of enrolled male and female students with male students comprising between $70 \%$ and $80 \%$ of the class.

\section{B. Physics 1B}

Physics $1 \mathrm{~B}$ is a second semester course introducing concepts of quantum physics and matter at large and small scales. Generally, the concepts addressed by Physics 1B will be much less familiar to the students than those in Physics 1A. The overwhelming majority of students in Physics 1B will have previously taken Physics 1A; however, not all students enrolled in Physics 1A will go on to study Physics 1B. The structure of the course is broadly similar to Physics 1A; however, experimental laboratory sessions replace the workshops. Problem solving skills are instead supported by shorter small-group tutorials. The exam is open book format and follows a broadly similar style to that of Physics 1A, with no multiple choice questions. In both courses the exam emphasis is strongly on applications and problem solving rather than factual recall or rote reproduction of results.

The demographics are broadly similar to those of Physics 1A (Table II), where approximately $70 \%$ of students are male.

\section{PeerWise scoring}

The PeerWise assessment was worth between $1 \%$ and $6 \%$ of the total mark, depending on the course. Marks were

TABLE II. Physics 1B student demographics.

\begin{tabular}{cccccc}
\hline \hline & $n$ class list & $n$ male & $n$ female & $n$ major & $n$ nonmajor \\
\hline $2011-12$ & 178 & 132 & 46 & 79 & 99 \\
$2012-13$ & 220 & 183 & 37 & 84 & 136 \\
$2013-14$ & 248 & 186 & 62 & 130 & 118 \\
\hline \hline
\end{tabular}


awarded based upon students' PeerWise score and having completed the minimum criteria. Each course stipulated a minimum number of questions to be authored, to be answered, and the number of comments to be given (Table III). In each course a PeerWise assignment replaced a "traditional" hand-in exercise, thus ensuring that students did not have an increased assessment load. Teaching staff did not monitor the system to ensure accuracy - the platform was regulated by students themselves, both in relation to academic quality and nonacademic disputes. Aside from small differences in the marking of the PeerWise assignment (see Table II), course structures remained the same across the study period. This suggested that performance for each course would be broadly comparable across the three academic years.

\section{Data collection methods}

Student views were obtained from online and in-class surveys In Physics 1B 2013-14, an in-class anonymous "minute paper" was used in place of an end of course questionnaire. Survey questions, including the question format and the method of data collection, are given in Table III together with the number of responses and response rate for each question, with the sources of the qualitative data in Table IV.

Physics 1B minute papers were administered in tutorials. Students were asked for written responses to three questions about their experience of using PeerWise, focusing mainly on the feedback given and received via the system.

This approach was chosen in order to maximize the response rate. It was administered in Physics $1 \mathrm{~B}$ as the vast majority of these students already had experience of using
PeerWise in Physics 1A. The questions were deliberately kept very open and general both to avoid over-constraining students' responses and to encourage reflection. Although themes arising from the minute papers could not be probed in real-time as they could, for example, in a focus group, this approach resulted in a more representative cross section of responses and hence enabled recurrent themes to emerge more easily.

Responses for each question were kept separately from each other, which meant that individual sets of responses could not be associated with a single (albeit anonymous) student. Attendance at tutorials is encouraged but not mandatory, which meant that a number of students were absent from class when the exercise was conducted. In addition, a handful of students submitted blank or "spoiled" response forms.

The open responses from all sources were coded in NVivo 10 using an approach loosely based on grounded theory [59], with each response broken down into key ideas and each idea given a code encapsulating the idea. As new ideas emerged, previously coded data were reclassified according to the new coding scheme, in a constant comparison process. The coding was undertaken by a single researcher, but following this iterative process and continually revisiting the data in light of the codes allowed definitional drift to be identified early, thus ensuring that the coding was reliable [60].

Each data source (questionnaire, minute paper question, etc.) was coded separately line by line and with a high level of granularity to enable checks to be made on the consistency $[61,62]$. This resulted in a plethora of codes and quite noisy data for each source so, where appropriate, codes were then combined into broader codes. For example, if one student

TABLE III. PeerWise requirements and marking scheme by course in each academic year studied.

\begin{tabular}{|c|c|c|c|}
\hline & 2011-2012 & 2012-2013 & 2013-2014 \\
\hline Phys. 1A & 3 deadlines & 2 deadlines & 2 deadlines \\
\hline Author & 3 & 2 & 2 \\
\hline Answer & 15 & 10 & 1 \\
\hline Comment & 9 & 6 & 6 \\
\hline$\%$ mark & $6 \%$ & $4 \%$ & $4 \%$ \\
\hline Scoring & $\begin{array}{l}\text { Meet min. requirements with lowest } \\
\text { PW score get } 40 \% \text {. Below this mark } \\
\text { linearly fitted between } 0 \text { and } 40 \% \text {. } \\
\text { Highest PW score completing min. } \\
\text { gets } 70 \% \text {-linear interpolation } \\
\text { between } 40 \text { and } 70 \% \text {. Max PW } \\
\text { score gets } 100 \% \text {-linear } \\
\text { interpolation between } 70 \text { and } 100\end{array}$ & $\begin{array}{l}\text { At least } 1 \text { question submitted but other } \\
\text { minima not satisfied: } 25 \% \\
\text { All minima satisfied and scoreboard } \\
\text { score below class median: } 75 \% \\
\text { All minima satisfied and scoreboard } \\
\text { score above class median: } 100 \%\end{array}$ & As in Physics 1A 2012-13 \\
\hline Phys. 1B & 1 deadline & 1 deadline & 1 deadline \\
\hline Author & 1 & 1 & 1 \\
\hline Answer & 5 & 5 & 5 \\
\hline Comment & 3 & 3 & 3 \\
\hline$\%$ mark & $1 \%$ & $1 \%$ & $1 \%$ \\
\hline Scoring & As in Physics 1A 2011-12 & As in Physics 1A 2012-13 & As in Physics 1A 2012-13 \\
\hline
\end{tabular}


TABLE IV. Sources of qualitative data.

\begin{tabular}{|c|c|c|c|c|}
\hline Question & Format & Course (Semester) & $n$ & $\begin{array}{c}\text { Response } \\
\text { rate }(\%)\end{array}$ \\
\hline What did you like best about the course & Online & $\begin{array}{l}\text { Physics 1A 2011-12, 2012-13 and 2013-14 } \\
\quad \text { (Semester 1) } \\
\text { Physics 1B 2011-12 and 2012-13 (Semester 2) }\end{array}$ & $19^{\mathrm{a}}$ & $5^{\mathrm{b}}$ \\
\hline What did you like least about the course & Online & $\begin{array}{l}\text { Physics 1A 2011-12, 2012-13 and 2013-14 } \\
\quad \text { (Semester 1) } \\
\text { Physics 1B 2011-12 and 2012-13 (Semester 2) }\end{array}$ & $48^{\mathrm{a}}$ & $13^{\mathrm{b}}$ \\
\hline $\begin{array}{l}\text { What aspect of PeerWise was most useful to } \\
\text { your learning and why did you find it useful? } \\
\text { If you did not find PeerWise useful, please } \\
\text { indicate your reasons }\end{array}$ & Online & Physics 1A 2013-14 (Semester 1) & 72 & 34 \\
\hline $\begin{array}{l}\text { What factors made you decide to answer, } \\
\text { comment on, or rate a particular question } \\
\text { in PeerWise? }\end{array}$ & Online & Physics 1A 2013-14 (Semester 1) & 72 & 34 \\
\hline $\begin{array}{l}\text { Do you feel you receive any benefits } \\
\text { yourself from giving feedback to others? } \\
\text { If so, what are they? If not, why not? }\end{array}$ & In-class & Physics 1B 2013-14 (Semester 2) & 129 & 52 \\
\hline $\begin{array}{l}\text { If you write a comment that is more than a } \\
\text { simple 'good question' type comment, } \\
\text { how do you decide what to write? }\end{array}$ & In-class & Physics 1B 2013-14 (Semester 2) & 129 & 52 \\
\hline $\begin{array}{l}\text { If someone comments upon one of your } \\
\text { questions how do you use this feedback? }\end{array}$ & In-class & Physics 1B 2013-14 (Semester 2) & 127 & 51 \\
\hline
\end{tabular}

\footnotetext{
${ }^{\mathrm{a}}$ Total number of responses across all courses and years that specify PeerWise as the best or worst aspect of the course.

${ }^{b}$ Percentage of responses across all courses and years that specify PeerWise as the best or worst aspect of the course.
}

said they disliked PeerWise (coded "dislike PeerWise"), and a second said they hated PeerWise (coded "hate PeerWise"), these codes were collapsed into a "dislike PeerWise" code. Although clearly there is a distinction between these two responses, both responses essentially indicated a negative feeling towards using PeerWise. Given the large amount of data and variety of themes, it was beyond the scope of this study to conduct such a more fine-grained analysis.

Upon completion of coding within each data source it was evident that there were broader themes emerging across several data sources with codes essentially highlighting the same issues - even though the actual question or focus of each source was slightly different. These

TABLE V. Theme 1: Community development $n=28$.

\begin{tabular}{ll}
\hline \hline Subtheme & \multicolumn{1}{c}{ Code } \\
\hline Sense of community & Collaboration and reciprocation \\
& Commented when thought it \\
would be useful \\
If question was helpful would \\
comment \\
Benchmark to gauge own learning \\
and gain new ideas \\
Learn more from staff than student \\
questions \\
No benefit from peer learning \\
Peer marking feels like lecturers \\
minimizing workload
\end{tabular}

duplicate codes were then merged into a single code across all the data sets. After rationalizing the codes in this way, the revised codes were then categorized into the emerging themes. Tables V-X show the codes within each theme.

In a grounded theory approach, the relationships between emerging themes are qualitative rather than quantitative. While numerical data such as code frequency are useful for identifying patterns and themes, they are not

TABLE VI. Theme 2: Compulsory nature $n=116$.

\begin{tabular}{ll}
\hline \hline Subtheme & \multicolumn{1}{c}{ Code } \\
\hline $\begin{array}{l}\text { Pragmatic approach } \\
\text { Assessed nature }\end{array}$ & Comment to fulfill requirements \\
Time spent & Should PeerWise was assessed \\
& Too many assignments \\
& Too much time writing questions \\
& nobody answers \\
& Too time consuming \\
& Dislike peer marking \\
& Favours easy questions \\
Marking & Got harder if previously had good \\
& marks \\
& Marking was uncertain \\
& Marks are dependent on others \\
& Score not indicative of quality \\
& Should be worth more \\
& Too many ways of cheating \\
& Too competitive \\
& Unfair grading and marks \\
\hline \hline
\end{tabular}


TABLE VII. Theme 3: Emotional response $n=37$.

\begin{tabular}{|c|c|}
\hline Subtheme & Code \\
\hline \multirow[t]{5}{*}{ Confidence } & $\begin{array}{l}\text { Competitive nature did not help } \\
\text { confidence }\end{array}$ \\
\hline & $\begin{array}{l}\text { Giving comments helps confidence/ } \\
\text { makes you feel good }\end{array}$ \\
\hline & $\begin{array}{l}\text { If comments are negative can be } \\
\text { discouraged }\end{array}$ \\
\hline & $\begin{array}{l}\text { Lack confidence in own knowledge to } \\
\text { write questions }\end{array}$ \\
\hline & Take confidence from positive feedback \\
\hline \multirow[t]{4}{*}{ Positive response } & Fun \\
\hline & Fresh approach \\
\hline & $\begin{array}{l}\text { Interact with question if interesting or } \\
\text { enjoyable }\end{array}$ \\
\hline & Interesting \\
\hline \multirow[t]{4}{*}{ Negative response } & Did not like PeerWise \\
\hline & PeerWise is a pain \\
\hline & Would rather do other assignments \\
\hline & Would rather do other course questions \\
\hline
\end{tabular}

TABLE VIII. Theme 4: Qualities $n=265$.

\begin{tabular}{|c|c|}
\hline Subtheme & Code \\
\hline Question difficulty & $\begin{array}{l}\text { Comment on the complexity of question } \\
\text { Difficult questions explained less well } \\
\text { Comment on level of difficulty } \\
\text { Issues had answering question instigates } \\
\text { discussion }\end{array}$ \\
\hline Feedback & $\begin{array}{l}\text { Better feedback given to unique questions } \\
\text { Feedback not constructive } \\
\text { Feedback often overly critical } \\
\text { Most feedback trivial and useless } \\
\text { Try to avoid writing poor quality } \\
\text { comments }\end{array}$ \\
\hline Quality of question & $\begin{array}{l}\text { Answered questions with a high rating } \\
\text { Comment on effort put in } \\
\text { Comment on error in question } \\
\text { Comment on why question is good or bad } \\
\text { Interact with question based on quality } \\
\text { Interact if question interesting or special } \\
\text { Many questions poor } \\
\text { Mix in quality of questions } \\
\text { Most questions good so don't need to } \\
\text { comment } \\
\text { Pick out negative aspects of question } \\
\text { Pick out positive aspects of question } \\
\text { Questions often off topic } \\
\text { Relate question and explanation to } \\
\text { marking scheme } \\
\text { Seek explanations and clarifications of } \\
\text { question in comments }\end{array}$ \\
\hline Structure or layout & $\begin{array}{l}\text { Comment on diagram, graphs or charts } \\
\text { Comment on distractors } \\
\text { Comment on explanation of method or } \\
\text { solution } \\
\text { Comment on layout } \\
\text { Comment on things disagree with }\end{array}$ \\
\hline
\end{tabular}

TABLE IX. Theme 5: Skills and learning $n=331$.

\begin{tabular}{|c|c|}
\hline Subtheme & Code \\
\hline Self-improvement & $\begin{array}{l}\text { Answering question helps knowledge and } \\
\text { understanding } \\
\text { Awareness of challenges of science } \\
\text { communication } \\
\text { Commenter does not receive benefits } \\
\text { from giving comments } \\
\text { Did not help revision } \\
\text { Does not seem to improve understanding } \\
\text { Helps to understanding how questions are } \\
\text { formulated } \\
\text { Helps understanding to look for features } \\
\text { in others' questions } \\
\text { Improved expertise and ability in giving } \\
\text { feedback } \\
\text { Practice problem solving skills } \\
\text { Rectify errors or problems in questions } \\
\text { Take feedback into account to improve } \\
\text { future questions } \\
\text { Understanding improved and knowledge } \\
\text { consolidated } \\
\text { Writing questions challenging } \\
\text { Writing questions most useful to learning } \\
\text { Writing questions not challenging as just } \\
\text { write easy ones }\end{array}$ \\
\hline Help others improve & $\begin{array}{l}\text { Give feedback based on whether the } \\
\text { question will help others } \\
\text { Try to write constructive criticism to help } \\
\text { in the future } \\
\text { Try to write something to help the } \\
\text { question author improve }\end{array}$ \\
\hline $\begin{array}{l}\text { Critical thinking and } \\
\text { reflection }\end{array}$ & $\begin{array}{l}\text { Decide if agree with comments } \\
\text { Don't use or read feedback } \\
\text { Comment if disagree } \\
\text { Read or think about feedback } \\
\text { Reflect on why comment was made } \\
\text { Think more deeply about the question } \\
\text { Use of feedback depends on its quality }\end{array}$ \\
\hline
\end{tabular}

directly relevant to the final stages of the analysis and interpretation of the data set. For this reason, quantitative measures are not presented in this paper.

While it may be argued that combining codes across data sets may result in a loss of the integrity of the data set as a whole-with the coded passages becoming decontextualized [63]-given the large number of sources, this was considered the most appropriate method to identify overarching themes highlighted by these introductory physics students. If students from different courses and different year groups, who answered different questions about PeerWise, highlighted similar issues, then this would indicate some level of generalizability of theme [64]. A number of codes did not fall under any overarching theme or were too trivial in terms of frequency to be considered a 
TABLE X. Theme 6: Usefulness $n=80$.

\begin{tabular}{|c|c|}
\hline Subtheme & Code \\
\hline Useful to learning & $\begin{array}{l}\text { Can be useful but not if left till the last } \\
\text { minute } \\
\text { Explanations useful } \\
\text { Found it useful } \\
\text { Good revision tools } \\
\text { Has potential to be useful } \\
\text { Increased course engagement } \\
\text { Instant feedback useful } \\
\text { Ratings useful for author } \\
\text { Variety of questions useful }\end{array}$ \\
\hline Not useful to learning & $\begin{array}{l}\text { Enjoyed it but not useful } \\
\text { Good idea but not greatly useful } \\
\text { No benefit } \\
\text { No educational value } \\
\text { Not useful } \\
\text { Not useful as unlike exam questions } \\
\text { Not useful but did use it for revision } \\
\text { Waste of time } \\
\text { Would benefit from other assignments }\end{array}$ \\
\hline
\end{tabular}

major theme. Although the data from which these codes were generated are rich, the purpose of this present work is to explore the most commonly recurring student views and attitudes towards PeerWise.

It is also worth highlighting that the free response questions had no prompts with regard to the type of comments students might make. It is therefore assumed that students highlighted issues that were most important to them. Nevertheless, it could also be the case that students felt limited in their time to consider and convey their thoughts so that their response does not necessarily encapsulate their entire view of the issue being discussed. It may be that when prompted, students may think about an aspect of their PeerWise experience that they had not previously considered. The themes highlighted in the open responses should therefore be treated as representing the most strongly held attitudes towards the system and considered a starting point upon which to base future research on student views of PeerWise.

\section{RESULTS}

Six main aspects of PeerWise were identified from the coding process, as shown in Tables $\mathrm{V}-\mathrm{X}$ : community development, compulsory nature, emotional response, quality, skills and learning, and usefulness. Each of these aspects of PeerWise engagement are discussed below, together with potential implications for encouraging future engagement with, and maximizing learning benefits gained from, the system.

\section{A. Community development}

Although not the most frequently occurring theme from the student responses, students did recognize the community aspect of the system. Given that engagement with PeerWise results in the establishment of a self-regulating peer-learning environment, and that its success is dependent on buy-in from students, this recognition is important. It seems to be the case that some students have developed a sense of community-an understanding that while there are course requirements for participation, the system itself requires participation in order to be an effective resource, so everyone can benefit from it. Several comments highlighted that sharing perspectives is important-students chose to provide feedback when they thought that their contribution would be useful to the community, or to commend another student on the helpfulness of their questions, thus providing support and encouragement for their peers.

"PeerWise works better when everyone collaborates". "If you receive feedback you end up giving feedback and so the cycle works".

"Sometimes I do not agree with it [feedback received] and it can lead to a debate, which is always useful in some way".

Students also recognized that sharing perspectives enhances their own learning.

"Giving feedback to other people's work can help you spot problems with your own work you might not otherwise have noticed or thought about".

"You realize your own level of physics in comparison with others".

While some students perceived there to be community benefits from engaging with PeerWise, there were others who disliked the peer interaction. They believed that the benefits gained from such exercises were minimal, in comparison to engaging with instructor questions.

"I don't like the PeerWise system because I think you learn more from questions written by Physics staff than questions written by other students".

Students will always have a preference for some types of learning activities over others, and for some students, engaging in group work or peer learning will be their least favorite mode of learning. If students are not aware of what such exercises are trying to achieve, and their potential benefits, then they will perhaps feel less motivated to engage with them. It is important that students understand the wider purposes of a task to ensure that even if it is not their preferred way of engaging with course materials, they can recognize the value of the exercise.

\section{B. Compulsory nature}

The compulsory nature of the PeerWise assignments was a consistent source of contention. Students stated that they engaged with the system to increase their score, or because the assignment was assessed and therefore compulsory. 
"Comment because I am assessed on them!"

"Just an assignment to be completed as quickly as possible”.

Some students felt that there was a tendency to prioritize gaining points over engaging deeply, or testing themselves as rigorously as they could. This contrasts with the views of other students who recognize the collaborative nature of the system, and is indicative of the varying degrees of intrinsic and extrinsic motivation held by different students.

“... having to write a certain amount of comments leads to very useless and redundant feedback with unnecessary comments".

"In all honesty I usually picked the easiest questions so I could quickly get it over with and revise and maybe do something that was, in my opinions more important".

Although a few students were glad the PeerWise assignment was assessed, students generally felt it would have been better had it not been assessed. Given the split opinion about the benefits of PeerWise, and the findings from previous studies $[51,54,65]$, it would seem doubtful whether in practice the level of engagement would be as high if PeerWise did not contribute a small part towards the course grade.

"Only use it if I must, that is when it is an assignment".

"Once I've done the required work I stop using Peer-

Wise. I only use it because it is marked".

The value of the PeerWise assignment within the overall course grade also resulted in some dissatisfaction. The need to balance PeerWise requirements with the summative value of the assignment has been highlighted previously-some students may prioritize it over other elements of the course, perhaps becoming too absorbed in the task [56], while others feel that the marks assigned to the assignment are disproportionate to the requirements $[56,66]$. The time-consuming nature of peer assessment activities in general is a recurring theme in the literature $[8,45,67]$.

"PeerWise might be good. But I found it extremely time consuming"

Some students said they were not certain about what they had to do to gain high marks and that they were competing for marks. This again reflects the student mistrust towards peer marking and assessment and the need for clarity and certainty in marking criteria. That students felt the system could become overcompetitive may even undermine the collaborative environment PeerWise is intended to foster.

"I understand how it is marked but it just didn't make sense to me, comparing marks with other people it is really hard to see where you have gone wrong and therefore I really don't know what I need to work on most or how to learn from my low grade".
Additionally, there was again the view that the marking scheme focused on activity rather than rewarding highquality submissions-potentially pitting students who wanted to put in effort to submit tricky questions against those who submitted easy questions because they would be answered more often and given more "likes".

"It was easy to just answer questions, rate and comment to get good scores, which meant that you didn't have to write a good question to get top marks".

"PeerWise essentially turned into points games and the number of decent, good quality questions were heavily outnumbered by quick and easy non-thought-provoking questions that were there simply to allow the authors to rack up a lot of points through people answering them".

\section{Emotional response}

This theme captures situations where students essentially expressed an emotional response, saying they liked or disliked PeerWise, or mentioning their reaction to the assignment with regards to their feelings. Many of these responses were then expanded into statements that encapsulate some of the other themes.

Students often provided a simple, short response stating either their like or dislike of the system.

"I hate PeerWise it's one more password to remember".

"PeerWise was fantastic, it was such a fresh approach and I really enjoyed it".

Students also commented that giving comments and feedback made them feel good about themselves as they were able to help others, and positive feedback received from others helped their own confidence levels.

“... constructive comments boost confidence in your knowledge and understanding”.

"To some extent I became more comfortable with explaining concepts".

A small number of responses did, however, note that confidence could be broken by receiving negative comments or if the PeerWise community was becoming overcompetitive.

"If the feedback is really negative, I'd be very discouraged".

"The competitive atmosphere of PeerWise didn't suit the rest of the course and didn't really help boost confidence over course content".

In line with earlier work [10,45,68], students also commented on their lack of confidence, in terms of both writing questions and providing feedback. Students may dislike the peer marking aspect of the task because they feel they lack expertise, are unable to provide high quality 
feedback and do not trust their own knowledge, so are therefore not in a position to trust their peers to provide critique on their submissions [54]. Students may also feel uncomfortable in critiquing other's work and unconfident in letting others see their own work [10,69]. However, the anonymous nature of PeerWise may somewhat alleviate both this issue and the potential of personal bias to skew critiques [10].

"Not really because I'm never sure if I'm right in my corrections/feedback".

"Having to submit a question for PeerWise assessments. I frequently felt unconfident in my level of knowledge".

\section{Qualities}

The theme of quality was one of the most frequently recurring across all the data sources. It is important to note that the overarching theme of quality is not solely a judgment on the merits of student submissions but also includes observations on qualities and features of the question, including its difficulty. Students stated that they tended to give feedback on specific features of the question, such as layout; specific aspects of the question they disagree with (whether they are accurate or not); and on component parts of the question such as any diagrams that may have been incorporated, the distractors or the explanation or solution provided.

"Comment on the author's explanation of the answers".

"I comment about the potential traps the question leads you into with 'red-herring' data given".

In a similar manner, the ease or difficulty of a question was often highlighted by students, as was the complexity of the question as a whole. Many students mentioned that they looked at a question's difficulty before answering it. Some students highlighted that they would tend to answer an easy question rather than a difficult question, either to score easy points, feeding into the competitive nature of the system, or because they just wanted to get the assessment over and done with as quickly as possible. Indeed, when asked what made them decide to interact with a question, a number of students stated that the ease or rating were influential factors. This is consistent with a previous study of PeerWise use, in which students said they used ratings to determine which questions to answer-with higher quality questions getting more exposure [70]. That higher quality questions get more views should also be reassuring to those concerned with students being exposed to erroneous information.

"In all honesty I usually picked the easiest questions so I could quickly get it over with and revise..."

"Mostly random, but skipped questions which look like they will need a lot of work".
In terms of the quality of the feedback provided, opinions were generally very mixed. Many students felt that most feedback was trivial and not constructive, giving little benefit to the recipient. There was a general attitude that good questions did not require much constructive feedback and that most feedback just stated whether the question was good or useful or pointing out simple typographical errors. Previous studies have highlighted that questions with errors or that are poorly structured provide more opportunities for students to provide constructive criticism [71].

"I rarely have seen constructive comments on my questions. The better the question the less you need to say to the person who made it".

"No real feedback comment. I have bad spelling so usually it's just comments, or jokes to my spelling errors than the comments on the physics of the problem".

Such attitudes are reflected in the fourth subtheme- the quality of the question. Students tended to state that they write more constructive comments when there were errors in the question.

"I will write more than "good question" if the question has any noticeable flaws ...".

"I would only comment if I felt the question was flawed, confusing or wrong".

"commented when I found something wrong or some point not mentioned in the solution".

Students also commented if a question was particularly interesting or special-perhaps being humorous or having an interesting context.

"If there is an original use of physics knowledge required I will comment on that".

"If I write an in-depth comment it is generally because something stood out about the question whether this was a superb physics questions, some faulty logic or something funny".

Students took the opportunity in their comments to seek clarification, both when a question was confusing or badly explained, but also when there was a technical point that they did not understand. Students seeking clarification can improve their understanding, and the students giving the explanations may consolidate their understanding by explaining the problem further, or may find that they need to improve their own understanding of the problem if a comment probes a concept more deeply than the original question.

"If I see the explanation is poor either by requesting more help or providing it myself if I am confident with the topic".

"I usually either point out what may be wrong or unclear ..." 
Although students were keen to pick up on points of confusion or aspects which could be better explained, many students were also keen to assist the question author by using their comment to provide an alternative explanation or solution to the problem. This once again highlights a deep level of engagement with the PeerWise community and the potential richness of the system, with students taking ownership of their own learning and further developing the resource to increase its usefulness.

"Often there are other possible answers which have not been considered, so I would comment explaining other possible answers".

"I commented on questions for which the explanation used a different method than I did to arrive at the same answer".

\section{E. Skills and learning}

There are three main aspects of the development of skills and learning gained through the use of PeerWise. First, how engaging with PeerWise helps (or does not help) the student's own learning; second, how student engagement - especially through providing comments - can help (or not) others' learning; and third the extent to which skills of critical thinking and reflection can be enhanced. This was the most frequently highlighted theme in the student response, which is perhaps not surprising, given that PeerWise is intended to deepen understanding and enhance student learning.

There were mixed responses as to whether PeerWise enhanced a student's own learning, and in terms of which aspects of the system were best placed to do this. Some students simply stated that using PeerWise did or did not have any effect on their learning. Others provided more detailed comments, explaining that either answering questions or writing questions helped their knowledge and understanding. Some students stated that they found writing questions very difficult and that they had to be secure in their own knowledge before they could author a question. Similar findings have been reported previously, with students feeling under pressure to write questions while simultaneously trying to understand the concepts [58]. Writing questions is also known to be a difficult task $[67,72]$. Some students highlighted that feedback could be used to rectify errors or problems in their questionlearning from their mistakes.

"I don't feel it had any impact on my physics knowledge".

"It is good as a revision tool for some people but that person isn't me".

"Making question was good for consolidating my learning".

"Made me concentrate on a specific area of physics and get really good at it by making a question".
"It was also good to look at the different ways things were explained, so if there were two similar questions, it was helpful to look at both explanations".

"I found PeerWise as a whole an amazing resource, adding over 500 questions to the many questions that the course already has. I enjoyed going through and finding both simple review questions on basic understanding from the beginning of the course and complex questions on a combination of the more recent topics".

“... answering other questions were useful as sometimes they were a bit different to other questions we might have seen before".

The views of the students surveyed in the current work are broadly in line with opinions highlighted in the literature in relation to the enhancement of their knowledge and understanding. Students have stated that engaging with question generation activities increases their depth and breadth of knowledge [54]. More generally, they feel that writing questions increases engagement in terms of the time spent learning and through motivating personal exploration of the subject matter $[8,67]$.

Some students felt that providing comments did not benefit their learning and that the recipient of the feedback benefited most. However, others noted that assessing their peers' questions helped their own understanding and improved their ability to provide feedback.

"I get benefit from doing the question itself, rather than giving written feedback"

"I feel I am only giving the feedback to help the other person with their mistakes".

"I am compelled to think how to improve their questions and I thus reflect more on how to write a good question myself".

Some students focused on the fact that writing questions helped their own question writing skills - and enabled them to write better questions and to appreciate the other side of the question writing process.

"If the comment is thought about properly then you have to examine the question to find good/bad aspects and put yourselves in the shoes of the question writer. This makes you a better question writer yourself but not necessarily better at the subject the question is about".

"Makes me consider the components of a good question and so assists me in writing my own questions".

"PeerWise was quite interesting. It was good to see "the other side" of the process".

It is not clear from these responses whether students wrote better questions because their understanding was enhanced or because they were more aware of how a good question was constructed. Both outcomes clearly enhance learning to some degree, but it would not be optimal if students were focusing on the mechanics of question 
writing rather than stretching their knowledge and understanding. Indeed, it has been highlighted that question generation activities could have a negative impact on learning if students focus on the mechanics of question generation more than on the content [67].

Students also demonstrated a desire to help others improve their own knowledge and understanding, reflecting the sense of community and responsibility students felt towards their peers.

"Something I believe the author could use to better this question and future questions".

"Mostly I try to identify areas which can be improved and suggest ideas".

While students were not assessed on providing feedback, being able to critically engage with a piece of work, apply standards to assess its quality, then transfer these standards to one's own work is an extremely valuable skill. The issue of students not using, or even reading, feedback-failing to close the feedback loop-is widely highlighted in the feedback and assessment literature and has also arisen in the context of PeerWise [71]. Although it has been stated that receiving feedback is a bonus, and that the main benefit to students may be in providing the critique, a failure to engage with feedback means that there will certainly be no chance of any bonus benefits arising from the receipt of the feedback [33].

"Don't use it. Just want marks".

"I don't usually bother to read it".

"Keep it in mind when writing my next question I guess (well I don't know really, I guess I should but that doesn't happen all that often) usually I go 'alright' and forget about it".

Many students stated that their use of received feedback depended on its quality, and specifically that they assess the feedback, reflecting upon the reasons why comments were made, and deciding whether they agree with them, rather than automatically altering their question or point of view without coming to an opinion about whether the critique is valid. This shows engagement with the feedback, critically reflecting upon its validity-and thus closing the feedback loop.

"I carefully read all the comments and sometimes find constructive and useful feedback which I may use to improve the questions in future".

"I try first to understand what they mean and whether I agree with their feedback".

"I use feedback by understanding where that person is coming from and help improve my understanding".

In providing feedback, students need to make an assessment about the question. Students stated that this means they have to think more deeply about the question-enhancing understanding and developing a more analytical approachrather than simply selecting an answer.

"Consequently, I am now better capable of criticizing seemingly obvious flaws made in scientific calculations" "It forces me to try and be helpfully critical of people's work. A skill that is valuable when running a team or business operation".

"Commenting on others' questions is useful as you analyze the question more closely".

\section{F. Usefulness}

Students often commented on the general usefulness of engaging with PeerWise-finding it either useful or not useful to their learning. If students perceive an exercise to be useful then they may be more inclined to engage with it and view it not just as a means of completing an assignment, but to help their learning and skills development. Perhaps unsurprisingly, some students found PeerWise very useful, while others did not feel they gained any particular benefit from it. It is worthwhile considering why students did not find PeerWise useful in order to address any issues that could improve their experience of using the system.

It has been suggested that if the exam format does not match the PeerWise exercise (i.e., if there are no question setting or multiple choice questions included in the exam), then this could make students view PeerWise as being less useful to their learning [58]. It is certainly the case that in Physics 1A and 1B there are no multiple choice questions in the exam. However, many of the negative comments did not elaborate on why PeerWise was not useful-rather just stating it was a waste of time, or pointless, or simply not useful. A few students did, however, elaborate on the elements of the system that they did not find beneficial.

"No as all I'm saying is how well they have done on a particular question, doesn't benefit me".

"No I generally don't get any benefit from PeerWise".

"I don't use it. It won't change anything. PeerWise is not useful".

"I enjoyed PeerWise, but didn't find it extremely useful".

On the other hand, many students were more positive about the impact PeerWise had on their learning. In a similar manner to the students who did not find it useful, some students wrote quite simple comments, not really expanding upon why they found engaging with the system beneficial. There were several respondents who did respond in more detail.

"I found the explanations quite useful to see what I had done wrong".

"It forced me to do more homework problems". 
The variety of questions in terms of difficulty and subject area was also considered useful. Students deemed PeerWise to be a good source for revision-even if they did not like participating in the actual exercise- thus they recognized that it could be a beneficial resource.

"PeerWise had a large variety of questions to answer on areas of all the course which was useful".

"The sheer diversity of questions available was very helpful".

\section{DISCUSSION}

It is evident both from this and from other studies that students' views about the incorporation of PeerWise into course assessments are mixed [68]. Some do not believe PeerWise to have any educational benefit. However, a large proportion of students recognize benefits of engaging with the system - that it fosters a sense of community and allows them to engage in both peer and self-assessment. This type of collaboration is considered an extremely powerful aspect of learning [3,11,54,66,73]. Engaging with their peers, particularly while participating in learning activities that result in student-generated resources, encourages students to become active participants in their own learning [3-5]. Expressing their opinions and ideas develops students' sense of ownership over their learning, thus increasing their focus and motivation to learn $[8,10,66]$.

Some students recognize that engaging with peers, sharing and developing knowledge provides a benchmark by which to gauge their own learning and may highlight different ways to approach problem solving. Students' understanding can be enriched and problems clarified by drawing on the collective resources, or capital, held by their classmates [74]. Indeed, being able to assess one's own understanding in relation to that of others has been highlighted as a key benefit of peer assessment and collaboration, both in relation to PeerWise $[54,56,66]$ and, more generally, Refs. [10,11].

Students often recognize the benefits of writing, as well as answering, questions. However, they may fail to recognize that providing feedback can sometimes be more beneficial than receiving feedback. When students read feedback, they tend to reflect upon it to assess whether the feedback is worth acting upon rather than engaging more deeply with it. This reflection perhaps stems from a mistrust of their peers' ability to provide useful feedback; however, it may suggest that the feedback loop is, at least in some sense, being closed, with students perhaps being encouraged to think more deeply about feedback they receive in the future.

Student responses also highlight the importance of setting clear standards and expectations for assessment. Not surprisingly, the issue of fairness is also crucial. Students have invested a significant amount of time, effort, and money in their education and it is only natural that they expect their marks to be "safe" and fair and do not want to lose out due to perceived unfairness. Many students also feel anxious over peer assessment and group work. They worry both about their own ability to contribute and about the ability of their peers. If marking schemes and standards are unclear, this may exacerbate concerns they already hold about engaging with their peers.

There is a clear tension between contributing quality submissions and engaging at a surface level to fulfil the assessment requirements. The assessment structure can significantly influence both the way students interact with the system and their satisfaction with the assessment requirements and sense of fairness. Although most instructors would view PeerWise primarily as a tool for formative assessment, it is often necessary to allocate some marks to encourage engagement. In the courses studied here, this is only between $1 \%$ and $6 \%$ of the overall course mark, but this is sufficient to motivate students and allow them to feel that their contribution is recognized. As with all (formative or summative) assessment activities, it is also vital that expectations are made clear at the outset, so that students are confident they understand what they need to do to perform at their best.

In the majority of reported studies, the motivation for using PeerWise is to promote deep learning and critical thinking. However, if marking schemes are based on a student's PeerWise score (which depends in part on other students' participation, e.g., the number of times a question has been answered), what is actually being valued is early participation, the submission of correct answers and, in effect, the popularity of student contributions [52]. It is therefore sometimes unclear whether there is alignment between this method of assessment and the somewhat "messy", developmental processes that PeerWise is seeking to promote [75]. It is perhaps preferable to assign marks based solely on students' own contributions, rather than being dependent on the actions of others. This acknowledges the efforts students make in creating and developing the resource, without penalty for testing ideas, venturing opinions, and clarifying areas of misunderstanding.

Although feedback is mixed, most students recognize that there is some value in engaging with PeerWise. Not all students enjoy or feel comfortable with every activity they face, and student opinion is dependent to a certain degree on how the task is implemented, including aspects such as the mark value assigned to it, the number of assignments to be completed, and the way marks are assigned. As with all assessed activities, clarity of expectation, fairness in marking, and explicitly informing students about the purpose of the exercise and the desired learning outcomes will go some way to enhance engagement and satisfaction with the PeerWise system. By asking students specifically about how they approach assessments, tasks can be more easily tailored to ensure they provide maximal benefit to their development.

PeerWise is, at heart, a resource created by and for students. It is clear from this study that encouraging 
students to take more ownership will benefit both them and their peers. Given this, one area that would especially merit future study is the use of co-creation activities to support PeerWise. In particular, involving students in setting assessment metrics and developing quality criteria for both questions and feedback could pay dividends in terms of developing a supportive learning community and helping students develop their skills and confidence.

\section{ACKNOWLEDGMENTS}

A. K. thanks the Higher Education Academy for a Ph.D. studentship through the Mike Baker Doctoral Programme. Thanks must also be extended to Dr. Paul Denny for providing PeerWise usage statistics for each of the courses analyzed. Finally, thank you to all the students whose contributions have been analyzed in the course of this work.
[1] B. Collis and W. de Boer, A changing pedagogy in E-learning: From acquisition to contribution, J. Comput. High. Edu. 13, 87 (2002).

[2] J. Hamer, Some experiences with the "contributing student approach", in ItiCSE (ACM, Bologna, Italy, 2006), pp. 68-72.

[3] B. Collis and J. Moonen, in Engaged Learning with Emerging Technologies, edited by M. Khine and D. Hung (Springer, New York, NY, 2006), pp. 49-67.

[4] J. Hamer, Q. Cutts, J. Jackova, A. Luxton-Reilly, R. Mccartney, H. Purchase, C. Riedesel, and K. Sanders, Contributing student pedagogy, Inroads-SIGCSE Bull. 40, 194 (2008).

[5] K. Falkner and N. J. G. Falkner, Supporting and structuring "contributing student pedagogy" in Computer Science curricula, Comput. Sci. Educ. 22, 413 (2012).

[6] F.-Y. Yu and Y.-H. Liu, Potential values of incorporating a multiple-choice question construction in physics experimentation instruction, Int. J. Sci. Educ. 27, 1319 (2005).

[7] S. S. Sircar and O. P. Tandon, Involving students in question writing: a unique feedback with fringe benefits, Adv. Phsyiology Educ. 277, S84 (1999).

[8] M. R. Fellenz, Using assessment to support higher level learning: the multiple choice item development assignment, Assessment and evaluation in higher education 29, 703 (2004).

[9] A. Luxton-Reilly and P. Denny, Constructive evaluation: A pedagogy of student-contributed assessment, Comput. Sci. Educ. 20, 145 (2010).

[10] C. Brindley and S. Scoffield, Peer assessment in undergraduate programmes, Teach. High. Educ. 3, 79 (1998).

[11] K. J. Topping, Peer assessment between students in colleges and universities, Rev. Educ. Res. 68, 249 (1998).

[12] G. Schraw, K. J. Crippen, and K. Hartley, Promoting selfregulation in science education: Metacognition as part of a broader perspective on learning, Res. Sci. Educ. 36, 111 (2006).

[13] C. Chin and D. E. Brown, Learning in science: a comparison of deep and surface approaches, J. Res. Sci. Teach. 37, 109 (2000).

[14] J. Hardy, S. P. Bates, M. M. Casey, K. W. Galloway, R. K. Galloway, A.E. Kay, P. Kirsop, and H. A. McQueen, Student-generated content: enhancing learning through sharing multiple-choice questions, Int. J. Sci. Educ. 36, 2180 (2014).

[15] A. E. Kay, J. Hardy, and R. K. Galloway (to be published).

[16] M. M. Casey, S. P. Bates, K. W. Galloway, R. K. Galloway, J. Hardy, A. E. Kay, P. Kirsop, and H. A. McQueen, Scaffolding student engagement via online peer learning, Eur. J. Phys. 35, 045002 (2014).

[17] M. M. Nelson and C. D. Schunn, The nature of feedback: How different types of peer feedback affect writing performance, Instr. Sci. 37, 375 (2009).

[18] M. T. H. Chi, N. Leeuw, M.-H. Chiu, and C. Lavancher, Eliciting self-explanations improves understanding, Cogn. Sci. 18, 439 (1994).

[19] N. Liu and D. Carless, Peer feedback: the learning element of peer assessment, Teach. High. Educ. 11, 279 (2006).

[20] J. Lu and N. Law, Online peer assessment: effects of cognitive and affective feedback, Instr. Sci. 40, 257 (2012).

[21] Y. H. Cho and K. Cho, Peer reviewers learn from giving comments, Instr. Sci. 39, 629 (2011).

[22] L. Li, X. Liu, and A. L. Steckelberg, Assessor or assessee: How student learning improves by giving and receiving peer feedback, Br. J. Educ. Technol. 41, 525 (2010).

[23] M. van Zundert, D. Sluijsmans, and J. van Merrinboer, Effective peer assessment processes: Research findings and future directions, Learn. Instr. 20, 270 (2010).

[24] Higher Education Funding Council for England, National Student Survey 2015 Summary Data (2015).

[25] A. Jonsson, Facilitating productive use of feedback in higher education, Act. Learn. High. Educ. 14, 63 (2012).

[26] G. Gibbs and C. Simpson, Conditions under which assessment supports students' learning, Learn. Teach. High. Educ. 3 (2004).

[27] N. Duncan, Feed-forward: improving students' use of tutors' comments, Assessment and evaluation in higher education 32, 271 (2007).

[28] L. Li, X. Liu, and Y. Zhou, Give and take: A re-analysis of assessor and assessee's roles in technology-facilitated peer assessment, Br. J. Educ. Technol. 43, 376 (2012).

[29] P. A. Ertmer, J. C. Richardson, B. Belland, D. Camin, P. Connolly, G. Coulthard, K. Lei, and C. Mong, Using peer feedback to enhance the quality of student online postings: An exploratory study, J. Comput. Commun. 12, 412 (2007).

[30] K. Cho, C.D. Schunn, and D. Charney, Typology and perceived helpfulness of comments from novice peer 
reviewers and subject matter experts, Writ. Commun. 23, 260 (2006).

[31] D. Nicol, A. Thomson, and C. Breslin, Rethinking feedback practices in higher education: a peer review perspective, Assessment and evaluation in higher education 39, 102 (2013).

[32] M. L. Wen and C.-C. Tsai, University students' perceptions of and attitudes toward (online) peer assessment, High. Educ. 51, 27 (2006).

[33] J. Hamer, H. Purchase, A. Luxton-Reilly, and P. Denny, A comparison of peer and tutor feedback, Assessment and evaluation in higher education 40, 151 (2014).

[34] D. Nicol and D. Macfarlane-Dick, Formative assessment and self-regulated learning: a model and seven principles of good feedback practice, Stud. Higher Educ. 31, 199 (2006).

[35] A. W. Chickering and Z. F. Gamson, Seven principles for good practice in undergraduate education, American Association of Higher Education Bulletin 39, 3 (1987).

[36] M. Taras, Using assessment for learning and learning from assessment, Assessment and evaluation in higher education 27, 501 (2002).

[37] Y. Woo and T. C. Reeves, Meaningful interaction in webbased learning: A social constructivist interpretation, Internet High. Educ. 10, 15 (2007).

[38] C. Chin, Learning in science: What do students' questions tell us about their thinking?, Educ. J. 29, 85 (2001).

[39] D. Boud and E. Molloy, Rethinking models of feedback for learning: the challenge of design, Assessment and evaluation in higher education 38, 698 (2013).

[40] C. Rust, The impact of assessment on student learning, Act. Learn. High. Educ. 3, 145 (2002).

[41] D. Nicol, The Foundation for Graduate Attributes: Developing Self-Regulation through Self and Peer Assessment (2010).

[42] D. Sluijsmans, F. Dochy, and G. Moerkerke, Creating a Learning Environment by Using Self-, Peer- and CoAssessment, Learn. Environ. Res. 1, 293 (1999).

[43] K. Cho and C. MacArthur, Learning by reviewing, J. Educ. Psychol. 103, 73 (2011).

[44] F.-Y. Yu, Multiple peer-assessment modes to augment online student question-generation processes, Comput. Educ. 56, 484 (2011).

[45] S. J. Hanrahan and G. Isaacs, Assessing Self- and Peerassessment: The students' views, Higher Educ. Res. Dev. 20, 53 (2001).

[46] P. Donovan, Closingthe feedback loop: physics undergraduates' use of feedback comments on laboratory coursework, Assessment and evaluation in higher education 39, 1017 (2014).

[47] S.-C. Tseng and C.-C. Tsai, On-line peer assessment and the role of the peer feedback: A study of high school computer course, Comput. Educ. 49, 1161 (2007).

[48] S. Gielen, E. Peeters, F. Dochy, P. Onghena, and K. Struyven, Improving the effectiveness of peer feedback for learning, Learn. Instr. 20, 304 (2010).

[49] R. Higgins, P. Hartley, and A. Skelton, The Conscientious Consumer: Reconsidering the role of assessment feedback in student learning, Stud. Higher Educ. 27, 53 (2002).

[50] D. R. Sadler, Formative assessment and the design of instructional systems, Instr. Sci. 18, 119 (1989).
[51] P. Denny, A. Luxton-Reilly, and J. Hamer, Student use of the PeerWise system, ItiCSE 40, 73 (2008).

[52] S. Bottomley and P. Denny, A participatory learning approach to biochemistry using student authored and evaluated multiple-choice questions, Biochem. Mol. Biol. Educ. 39, 352 (2011).

[53] L. Singh, Technology enhanced peer learning with PeerWise: experiences and perceptions from a developing country, Caribb. Teach. Sch. 4, 5 (2014).

[54] S. M. Rhind and G. W. Pettigrew, Peer generation of multiple-choice questions: student engagement and experiences, J. Vet. Med. Educ. 39, 375 (2012).

[55] P. Denny, Students learn by generating study questions but the content matters!Website: https://peerwise .cs.auckland.ac.nz/docs/community/students_learn_by_ generating/ (2014).

[56] B. J. Ryan, Line up, line up: using technology to align and enhance peer learning and assessment in a student centred foundation organic chemistry module, Chem. Educ. Res. Pract. 14, 229 (2013).

[57] A. MacRaighne, M. M. Casey, R. Howard, B. Ryan, A. Mac Raighne, M. M. Casey, R. Howard, and B. Ryan, Student attitudes to an online, peer-instruction, revision aid in science education, J. Perspect. Appl. Acad. Pract. 3, 49 (2015).

[58] P. Denny, B. Hanks, B. Simon, and S. Bagley, in Proceedings of the seventh international workshop on Computing education research (ACM, 2011), pp. 53-59.

[59] K. Charmaz, in SAGE Handbook of Social Research Methods, edited by L. Bickman and P. Alasuutari, and J. Brannen (Sage Publications Ltd., London, 2008), pp. 461-479.

[60] G. R. Gibbs, Analyzing Qualitative Data (Sage, London, 2007).

[61] K. Charmaz, in Encyclopedia of Social Science Research Methods, edited by M.S. Lewis-Beck, A. Bryman, and T. F. Liao (SAGE Publications, Inc., Thousand Oaks, CA, 2004).

[62] P. Bazeley and K. Jackson, Qualitative Data Analysis with NVivo, 2nd ed. (Sage, Los Angeles, 2013).

[63] L. Cohen, L. Manion, and K. Morrison, Research Methods in Education (Routledge, London, 2007).

[64] A. Bryman, Social Research Methods, 4th ed. (Oxford University Press, Oxford, 2012).

[65] J. Devon, J. H. Paterson, D. C. Moffat, and J. McCrae, Evaluation of student engagement with peer feedback based on student-generated MCQs, Innov. Teach. Learn. Inf. \&Comput. Sci. 11, 27 (2012).

[66] A. S. C. Hooper, S. J. Park, and G. Gerondis, Promoting student participation and collaborative learning in a large Info 101 class: student perceptions of PeerWise web 2.0 technology, in Proceedings of Higher Education Research and Development Society of Australasia International Conference (HERDSA,2011).

[67] A. L. Pittenger and J. L. Lounsbery, Student-generated questions to assess learning in an online orientation to pharmacy course, Am. J. Pharm. Educ. 75, 94 (2011).

[68] A. Sykes, P. Denny, and L. Nicolson, PeerWise - The marmite of veterinary student learning, in Proc. 10th Eur. Conf. E-Learning, edited by S.G. and A. Rospigliosi 
(Academic Conferences Ltd, England, 2011), Vols. 1 and 2, pp. 820-830.

[69] M. Barak and S. Rafaeli, On-line question-posing and peerassessment as means for web-based knowledge sharing in learning, Int. J. Hum. Comput. Stud. 61, 84 (2004).

[70] P. Denny, A. Luxton-Reilly, and B. Simon, in Proceedings of 11th Australasian Computing Education Conference (Wellington, New Zealand, 2009), pp. 55-63.

[71] J. H. Paterson, J. Devon, J. McCrae, D. C. Moffat, and E. Gray, Enhancing the Quality of Student-Generated MCQ's: A Fnal Report (Glasgow Caledonian University, Glasgow, 2011).
[72] E. Palmer and P. Devitt, Constructing multiple choice questions as a method for learning, Annals of the Academy of Medicine 35, 604 (2006).

[73] D. Boud, R. Cohen, and J. Sampson, Peer learning and assessment, Assessment and evaluation in higher education 24, 413 (1999).

[74] N. Lin, Building a network theory of social capital, Connecdtions 22, 28 (1999).

[75] J. Biggs and C. Tang, Teaching for Quality Learning at University, 4th ed. (Open University Press/McGraw-Hill Education, Maidenhead, 2011). 